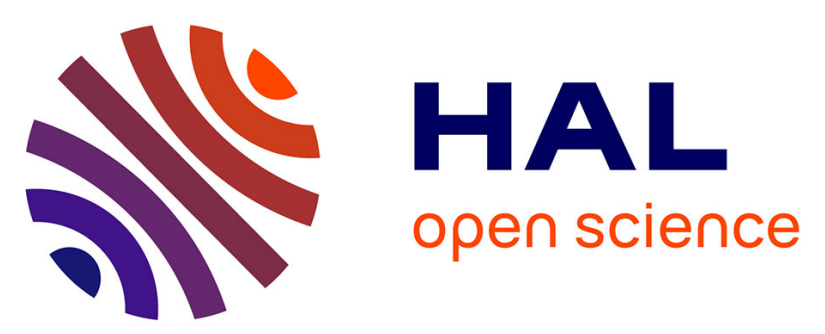

\title{
Elimination of Circulating Current in Wide Range LLC Resonant Converter with a Hybrid Bridge and Simultaneous PWM and PFM Control
}

\author{
Lingeshwaren Sobrayen, Charif Karimi, Patrick Dehem, Tanguy Phulpin, \\ Daniel Sadarnac
}

\section{To cite this version:}

Lingeshwaren Sobrayen, Charif Karimi, Patrick Dehem, Tanguy Phulpin, Daniel Sadarnac. Elimination of Circulating Current in Wide Range LLC Resonant Converter with a Hybrid Bridge and Simultaneous PWM and PFM Control. 2021 IEEE Applied Power Electronics Conference and Exposition (APEC), Jun 2021, Phoenix (virtual), United States. pp.327-334, 10.1109/APEC42165.2021.9487389 . hal-03403894

\section{HAL Id: hal-03403894 \\ https://hal.science/hal-03403894}

Submitted on 26 Oct 2021

HAL is a multi-disciplinary open access archive for the deposit and dissemination of scientific research documents, whether they are published or not. The documents may come from teaching and research institutions in France or abroad, or from public or private research centers.
L'archive ouverte pluridisciplinaire HAL, est destinée au dépôt et à la diffusion de documents scientifiques de niveau recherche, publiés ou non, émanant des établissements d'enseignement et de recherche français ou étrangers, des laboratoires publics ou privés. 


\title{
Elimination of Circulating Current in Wide Range LLC Resonant Converter with a Hybrid Bridge and Simultaneous PWM and PFM Control
}

\author{
Lingeshwaren Sobrayen* ${ }^{* \dagger}$, Charif Karimi* ${ }^{* \dagger}$, Patrick Dehem ${ }^{\ddagger}$, Tanguy Phulpin* ${ }^{* \dagger}$ and Daniel Sadarnac ${ }^{* \dagger}$ \\ *Université Paris-Saclay, CentraleSupélec, CNRS, Laboratoire de Génie Electrique et Electronique de Paris, \\ 91192 Gif-sur-Yvette, France \\ ${ }^{\dagger}$ Sorbonne Université, CNRS, Laboratoire de Génie Electrique et Electronique de Paris, 75252 Paris, France \\ ${ }^{\ddagger}$ EnerSys S.A.R.L., Rue A. Fleming - Z.I. EST - CS40962, 62033 Arras, France
}

\begin{abstract}
A hybrid bridge LLC-type converter is proposed for wide range dc-dc resonant conversion, to eliminate circulating current with the simultaneous use of pulsewidth modulation and pulse frequency modulation. The exact model of the converter is derived based on time domain analysis to aid design and control. Secondary side and output capacitor rms currents are significantly reduced, benefitting low output voltage/high power designs in terms of lower cooling and output filtering requirements. Absence of the $L_{\mathrm{m}}-L_{\mathrm{r}}-C_{\mathrm{r}}$ resonance interval, also suppresses secondary side parasitic ringing and can help to mitigate EMI issues. A GaN-based prototype of the converter is built and tested at 400V/18-36V, 500W. Analytical and experimental comparisons made with a standard LLC converter as well as with an alternative fixed frequency modulation scheme, validate the reduction of rms currents enabled by the proposed method and its potential for increased efficiency at higher power levels.
\end{abstract}

\section{INTRODUCTION}

The LLC resonant converter [1] (Fig. 1) is today one of the most established topologies for isolated dc-dc resonant conversion due to its simple circuit structure, soft switching characteristics, ability to regulate to zero load and scope for magnetic integration.

While the performance of the LLC resonant converter in terms of power density and efficiency can hardly be matched for medium to high frequency operation, its superiority is more contestable in wide input/output range applications. The LLC converter is preferably employed in the DCMB2/PO mode [2] [3] where its inverting bridge ZVS + rectifying bridge ZCS [4] characteristic can be exploited. With the isolation transformer turns ratio, $n$ designed to place the minimum gain requirement at the series resonant point, when the switching frequency, $f_{\mathrm{s}}$ is pulled down towards the parallel resonant frequency to attain higher gains as shown in Fig. 2(a), the more prominent the parallel resonant facet of the LLC converter becomes as an increasing amount of circulating current is introduced in the primary side of the circuit.

This behaviour is illustrated in Fig. 2(b) where the resonant current $i_{\mathrm{Lr}}$, the magnetizing current $i_{\mathrm{Lm}}$ and output side diode currents $i_{\mathrm{D} 1 / 4}$ are shown for the minimum and maximum gain points in a wide range design where $M_{\min }=1$ and $M_{\max }=2$. Ignoring the short deadtime interval that is

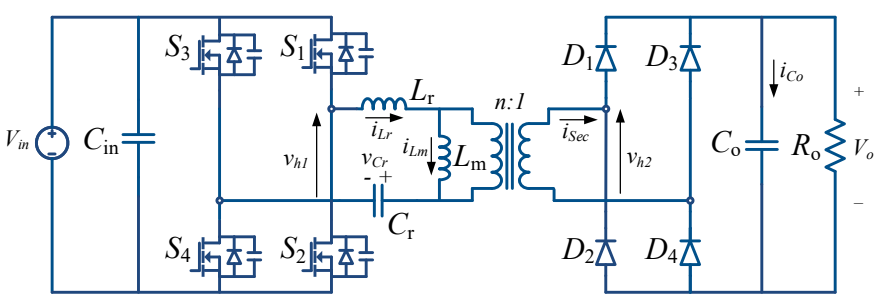

Fig. 1. The LLC resonant connverter

normally allowed, for $M_{\mathrm{min}}, i_{\mathrm{Lr}}$ and $i_{\mathrm{Lm}}$ become equal at half of the switching period, $T_{\mathrm{S}} / 2$ just before the primary bridge is switched to invert the polarity of the square wave being applied to the resonant tank. The magnetizing inductance $L_{\mathrm{m}}$ does not participate in resonance but only ensures a minimum tank current level to assist the ZVS turn-on of incoming switches. The primary and secondary sides of the converter are always connected and power transfer from the input to the output is distributed over the entire switching period $T_{\mathrm{S}}$ through the diodes that operate in boundary conduction mode.

At $M_{\max }$, the direct power transfer interval is drastically reduced - the instant when $i_{\mathrm{Lr}}$ equals $i_{\mathrm{Lm}}$ occurs very early in every half switching period. The input and output sides of the converter are disconnected at $t_{1}$, and all of the input source energy flows into $L_{\mathrm{m}}$ for $t_{1} \leq t<T_{\mathrm{s}} / 2$ building up its current for voltage boost operation. On the output side, diodes do not conduct and the load, $R_{\mathrm{O}}$ is fed from the output capacitor, $C_{\mathrm{o}}$. The prolonged zero power interval not only increases the circulating current on the primary side, but also increases the peak and rms currents of the output bridge rectifier that operates in highly discontinuous conduction mode. This results in increased conduction losses for the converter, when compared to the case where the input or the output voltage corresponding to that maximum gain point had been placed at the series resonant point.

As a solution to this inherent problem of wide range LLC resonant converters, a new modulation scheme based on a modified primary bridge [5]-[8], with the addition of two switches giving access to the input dc bus midpoint, 


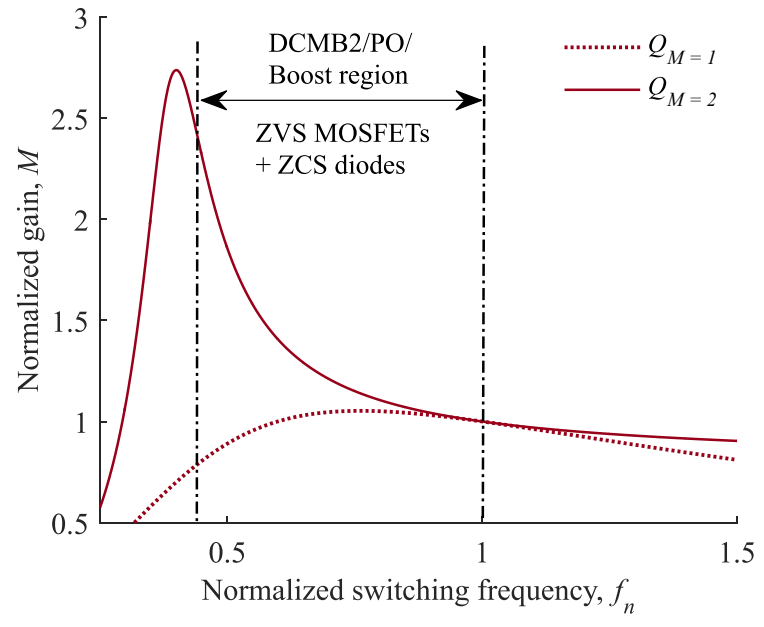

(a)

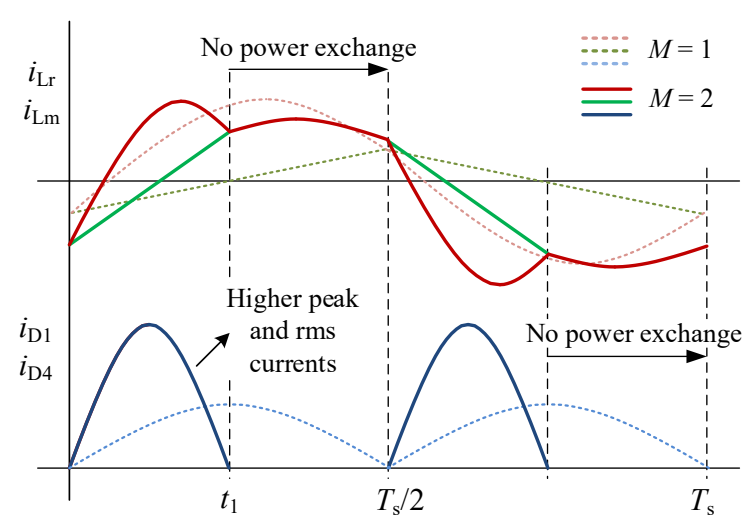

(b)

Fig. 2. (a) Gain v/s frequency characteristics of LLC converter for quality factors corresponding to $M=1$ and $M=2$ at constant power and (b) comparison of LLC resonant current $i_{\mathrm{Lr}}$, magnetizing current $i_{\mathrm{Lm}}$ and diode currents $i_{\mathrm{D} 1 / 4}$ for conversion gains $M=1$ and $M=2$

is proposed. This introduces a new voltage level $V_{\text {in }} / 2$ into the system, which in essence gives the primary bridge the ability of alternating between a half bridge and a full bridge configuration within the same switching cycle. The modulation strategy combines the duty ratio control of two possible voltage levels $V_{\text {in }}$ and $V_{\text {in }} / 2$ that can be imposed onto the resonant tank along with the frequency of their application to achieve two control objectives - traditional voltage regulation and elimination of the zero power exchange intervals/circulating currents in the converter within a gain range $M \in\left[\begin{array}{ll}0.5 & 1\end{array}\right]$, that corresponds to a gain range $M \in\left[\begin{array}{ll}1 & 2\end{array}\right]$ for a regular LLC converter with same input and output voltage specifications.

Usage of combined pulsewidth modulation (PWM) and pulse frequency modulation (PFM) can be found in [9], [10] but they are employed in distinct operating intervals and/or to address different problems: in [9] PFM is applied during regular operation and PWM control is applied only in abnormal condition for hold up time compensation, while the hybrid control method is used to address microcontroller limitations at high frequencies in [10]. A similar hybrid bridge

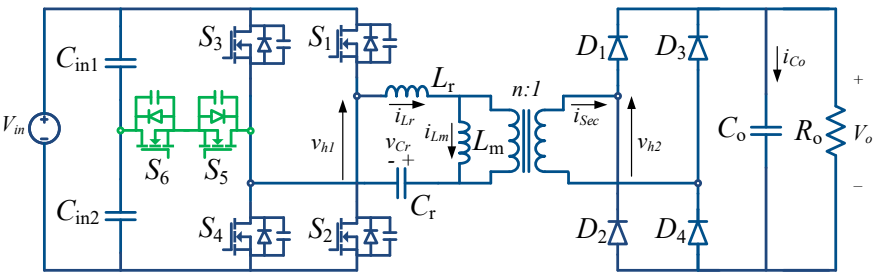

Fig. 3. Proposed two-parameter controlled hybrid bridge LLC resonant convereter

LLC resonant converter, is reported in [7] but the resulting topology is controlled by PWM only at fixed frequency to facilitate magnetics and filter designs; circulating currents still exist and compromise efficiency.

The paper is organized as follows: Section II describes the operation of the converter with the proposed modulation scheme. Time domain analysis is applied to derive the converter model in Section III from which its characteristics are determined and explained. The performance of the converter, evaluated through comparisons with a benchmark LLC design and a fixed frequency modulation technique for the hybrid bridge LLC topology is presented in Section IV. Experimental validation and further comparative analysis is performed on a $400 \mathrm{~V} / 18-36 \mathrm{~V}, 500 \mathrm{~W}$ prototype in Section V.

\section{MOdulation SCHEME AND CONVERTER OPERATION}

The modulation drives all six switches at a certain switching frequency, $f_{\mathrm{s}}$ while simultaneously adjusting the duty ratio, $D$ of the T-type leg to achieve two targets - gain setpoint and elimination of the zero power exchange intervals/circulating currents in the converter. More specifically, three complementary switch pairs can be identified: $S_{1}\left(\overline{S_{2}}\right)$, $S_{3}\left(\overline{S_{5}}\right)$ and $S_{4}\left(\overline{S_{6}}\right) . S_{1}$ and $S_{2}$ have a fixed duty ratio of 0.5. $S_{4}$ is controlled at a particular duty ratio and its rising edge is synchronized with that of $S_{1} . S_{4}$ conduction interval represents full-bridge mode of operation while its complementary switch $S_{6}$ conduction interval represents halfbridge mode of operation during a positive half cycle. Opposite phase complementary switches $S_{3}$ and $S_{5}$ are controlled in a similar fashion, synchronized with $S_{2}$ for conduction during the negative half period.

The operation of the converter can be fully described by the time-domain evolution of the resonant current $i_{\mathrm{Lr}}$, the resonant capacitor voltage $v_{\mathrm{Cr}}$ and the magnetizing inductor current $i_{\mathrm{Lm}}$ during five equivalent circuit state intervals (Fig. 4 and Fig. 5) that make up half a switching period. Voltages, time, currents and frequency are normalized using the following bases: $V_{\text {base }}=V_{\text {in }}, t_{\text {base }}=\theta / \omega_{\mathrm{r}}, I_{\text {base }}=V_{\text {in }} / Z_{\mathrm{o}}$ and $f_{\text {base }}=f_{\mathrm{r}}$, where $V_{\text {in }}$ is the converter input dc bus voltage, $\omega_{\mathrm{r}}=1 / \sqrt{L_{\mathrm{r}} C_{\mathrm{r}}}$ is the resonant tank angular frequency, $Z_{\mathrm{o}}=\sqrt{L_{\mathrm{r}} / C_{\mathrm{r}}}$ is the resonant tank characteristic impedance and $f_{\mathrm{r}}=\omega_{\mathrm{r}} / 2 \pi$ is the resonant tank frequency. A normalized half period is given by

$$
\gamma=\omega_{\mathrm{r}} \frac{T_{\mathrm{s}}}{2}=\frac{\pi}{f_{\mathrm{n}}}
$$




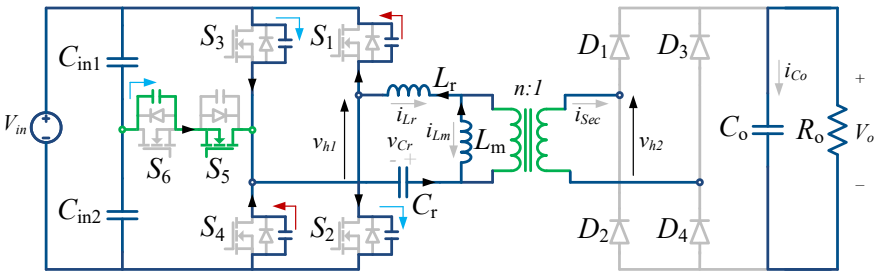

(a) Interval I: $t_{0} \leq t<t_{1}$

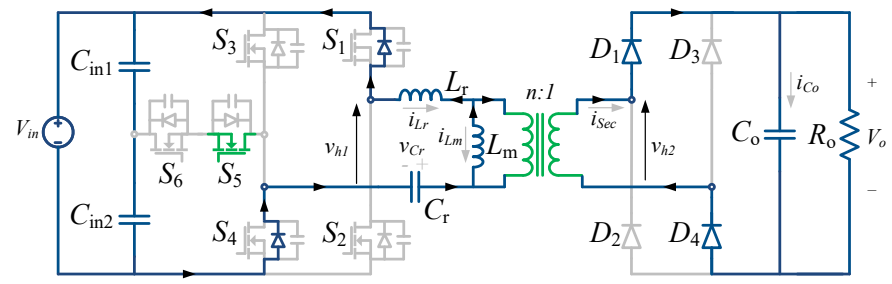

(b) Interval II: $t_{1} \leq t<t_{2}$

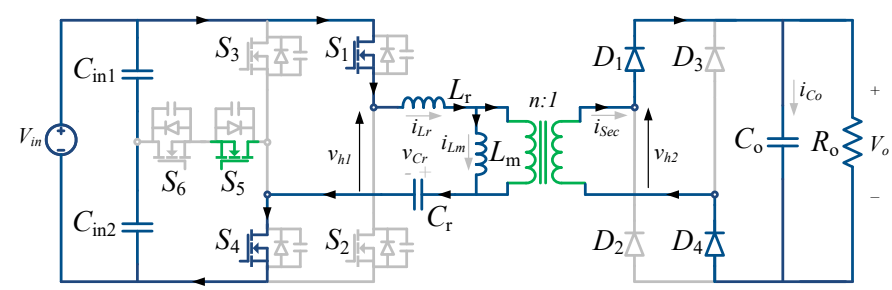

(c) Interval III: $t_{2} \leq t<t_{3}$

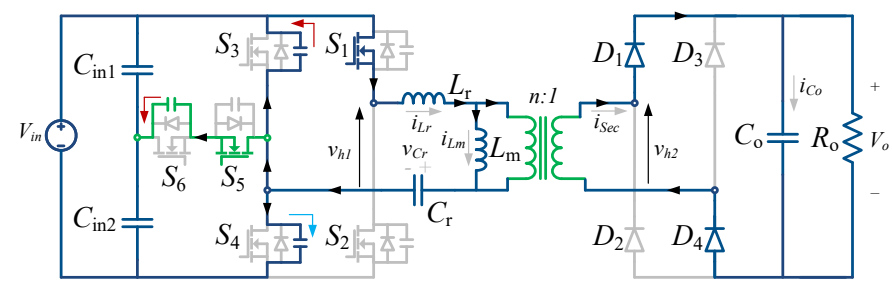

(d) Interval IV: $t_{3} \leq t<t_{4}$

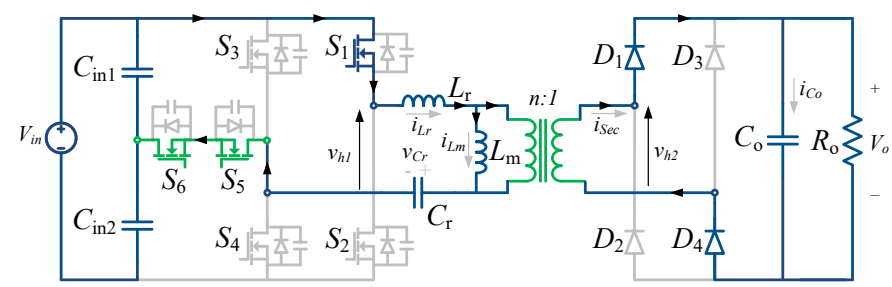

(e) Interval V: $t_{4} \leq t<t_{5}$

Fig. 4. Converter equivalent switching states during a positive half cycle

where $T_{\mathrm{s}}$ is the switching period and $f_{\mathrm{n}}$ is the normalized switching frequency, given by

$$
f_{\mathrm{n}}=\frac{f_{\mathrm{s}}}{f_{\mathrm{r}}}
$$

1) Interval $1\left(t_{0} \leqslant t<t_{1}\right)$ : Before $t_{0}$, during the negative half switching period, the converter was operating in half bridge mode, with switches $S_{2}, S_{5}$ and $S_{6}$ carrying the negative magnetizing current. At $t=t_{0}$, switches $S_{2}$ and $S_{6}$ are turned off. Charges on the switch output capacitances $C_{\text {oss } 1}-C_{\text {oss } 6}$ of the switch network $S_{1}-S_{6}$ start to redistribute themselves with the aid of the magnetizing current: 1) $C_{\mathrm{oss} 1}$

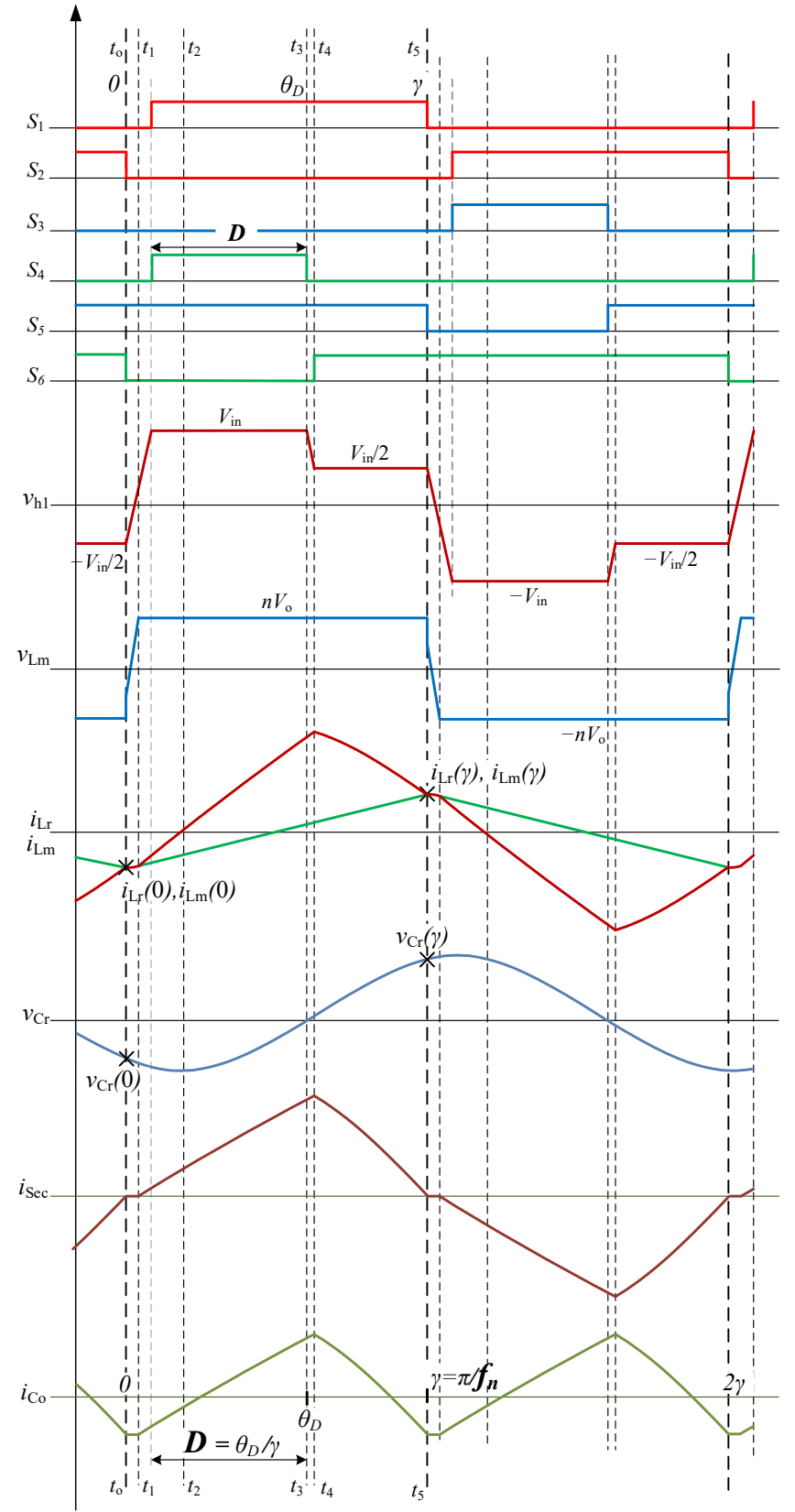

Fig. 5. Converter gating signals $S_{1-} S_{6}$, primary bridge voltage $v_{\mathrm{h} 1}$, magnetizing inductor voltage $v_{\mathrm{Lm}}$, resonant inductor current $i_{\mathrm{Lr}}$, magnetizing inductor current $i_{\mathrm{Lm}}$, resonant capacitor voltage $v_{\mathrm{Cr}}$, secondary bridge current $i_{\mathrm{Sec}}$ and output capacitor current $i_{\mathrm{Co}}$

starts discharging from $V_{\text {in }}$ to 0 ;2) $C_{\text {oss2 }}$ starts charging from 0 to $V_{\text {in }}$;3) $C_{\text {oss } 3}$ starts charging from $V_{\text {in }} / 2$ to $V_{\text {in }}$; 4) $C_{\text {oss } 4}$ starts discharging from $V_{\text {in }} / 2$ to 0 ;5) $C_{\text {oss } 5}$ is unaffected and remains discharged as $S_{5}$ is kept on; 6) $C_{\text {oss6 }}$ starts charging from 0 to $V_{\text {in }} / 2$.

The primary bridge voltage $v_{\mathrm{h} 1}$ starts inverting its polarity from $-V_{\text {in }} / 2$ to $V_{\text {in }}$ and the magnetizing inductor $L_{\mathrm{m}}$, part of a resonant tank being subjected to a linearly increasing excitation voltage $v_{\mathrm{h} 1}$, sees its voltage $v_{\mathrm{Lm}}$ rising as well. The input side and output sides of the converter are disconnected 
during this short deadtime interval, allowed to ensure 1) ZCS turn-off of diodes $D_{2}$ and $D_{3}$ that were conducting in the previous interval and 2) ZVS turn-on of $S_{1}$ and $S_{4}$ in interval 3.

2) Interval $2\left(t_{1} \leqslant t<t_{2}\right)$ : At $t=t_{1}, v_{\mathrm{Lm}}$ reaches the reflected output voltage $n V_{\mathrm{o}}$ and secondary side diodes $D_{1}$ and $D_{4}$ get forward biased and start to conduct to re-establish power transfer. On the primary side, body diodes of switches $S_{1}$ and $S_{4}$ start to conduct just after their respective $C_{\text {oss }}$ are completely discharged. The full dc bus voltage $V_{\text {in }}$ is applied to the resonant tank. Series resonance between elements $L_{\mathrm{r}}$ and $C_{\mathrm{r}}$ causes the primary current $i_{\mathrm{Lr}}$ to increase whereas $L_{\mathrm{m}}$ is clamped to the reflected output voltage $n V_{\mathrm{o}}$ and its current increases linearly. The difference between $i_{\mathrm{Lr}}$ and $i_{\mathrm{Lm}}$ reflected to the secondary side is fed to the output capacitor $C_{\mathrm{o}}$ and load resistor $R_{\mathrm{o}}$ through diodes $D_{1}$ and $D_{4}$. The normalized resonant inductor current $i_{\mathrm{Lr}}$, magnetizing current $i_{\mathrm{Lm}}$ and resonant capacitor voltage $v_{\mathrm{Cr}}$ are given by

$$
\begin{aligned}
i_{\mathrm{Lr}}(\theta)= & i_{\mathrm{Lr}}(0) \cos \theta+\left[1-M-v_{\mathrm{Cr}}(0)\right] \sin \theta \\
i_{\mathrm{Lm}}(\theta)= & i_{\mathrm{Lm}}(0)+M \theta / k \\
v_{\mathrm{Cr}}(\theta)= & 1-M-\left[1-M-v_{\mathrm{Cr}}(0)\right] \cos \theta \\
& +i_{\mathrm{Lr}}(0) \sin \theta
\end{aligned}
$$

where $M=n V_{\mathrm{o}} / V_{\text {in }}$ is the normalized output voltage or gain and $k$ is the resonant tank inductance ratio $L_{\mathrm{m}} / L_{\mathrm{r}}$. Gating signals of $S_{1}$ and $S_{4}$ can be applied from this point onward before the zero crossing of $i_{\mathrm{Lr}}$ for their ZVS turn-on.

3) Interval $3\left(t_{2} \leqslant t<t_{3}\right)$ : At $t=t_{2}, i_{\text {Lr }}$ polarity reverses and switches $S_{1}$ and $S_{4}$ turn on with ZVS. Currents and voltages of the resonant tank are still given by (3).

4) Interval $4\left(t_{3} \leqslant t<t_{4}\right)$ : At $t=t_{3}$, gating signal of $S_{4}$ is removed. Charges of switch output capacitances $C_{\text {oss } 3}-C_{\text {oss } 6}$ of the T-type leg start to redistribute themselves with the aid of the positive resonant tank current: 1) $C_{\mathrm{oss} 3}$ starts discharging from $V_{\text {in }}$ to $\left.V_{\text {in }} / 2 ; 2\right) C_{\text {oss } 4}$ starts charging from 0 to $V_{\text {in }} / 2$; 3) $C_{\text {oss } 5}$ is unaffected and remains uncharged as $S_{5}$ is kept on; 4) $C_{\text {oss6 }}$ starts discharging from $V_{\text {in }} / 2$ to 0 . Its body diode starts conducting hereafter, preparing for its ZVS turn-on. This interval marks the end of operation in full-bridge mode at $\theta=\theta_{\mathrm{D}}$, based on which the duty ratio of the converter is defined as $D=\theta_{\mathrm{D}} / \gamma$.

5) Interval $5\left(t_{4} \leqslant t<t_{5}\right)$ : At $t=t_{4}$, gating signal of $S_{6}$ is applied and turns on under ZVS; current flowing in its body diode is transferred to the MOSFET channel that starts conducting in synchronous rectification mode. The converter operates in half-bridge mode, with the resonant tank being excited by half of the dc bus voltage. The resonant tank normalized currents and voltages are now given by

$$
\begin{aligned}
i_{\mathrm{Lr}}(\theta)= & i_{\mathrm{Lr}}\left(\theta_{4}\right) \cos \left(\theta-\theta_{4}\right) \\
& +\left[0.5-M-v_{\mathrm{Cr}}\left(\theta_{4}\right)\right] \sin \left(\theta-\theta_{4}\right) \\
i_{\mathrm{Lm}}(\theta)= & i_{\mathrm{Lm}}\left(\theta_{4}\right)+M\left(\theta-\theta_{4}\right) / k \\
v_{\mathrm{Cr}}(\theta)= & 0.5-M-\left[0.5-M-v_{\mathrm{Cr}}\left(\theta_{4}\right)\right] \cos \left(\theta-\theta_{4}\right) \\
& +i_{\mathrm{Lr}}\left(\theta_{4}\right) \sin \left(\theta-\theta_{4}\right)
\end{aligned}
$$

\section{Converter Model ANd Characteristics}

Based on the development of the resonant tank state variables from (3) and (4), with the short deadtime intervals $t_{0} \leqslant t<t_{1}$ and $t_{3} \leqslant t<t_{4}$ ignored, and applying halfwave symmetry condition

$$
\begin{aligned}
i_{\mathrm{Lr}}(\gamma) & =-i_{\mathrm{Lr}}(0) \\
v_{\mathrm{Cr}}(\gamma) & =-v_{\mathrm{Cr}}(0)
\end{aligned}
$$

tank currents equivalence at half period

$$
i_{\mathrm{Lr}}(\gamma)=i_{\mathrm{Lm}}(\gamma)
$$

power transfer equivalence over half period

$$
\frac{1}{\pi} \int_{0}^{\pi}\left(i_{\mathrm{Lr}}(\theta)-i_{\mathrm{Lm}}(\theta)\right) d \theta=I_{o}=\frac{8 M Q}{\pi^{2}}
$$

where the quality factor $Q$ is given by

$$
Q=\frac{\pi^{2} Z_{\mathrm{o}}}{8 n^{2} R_{\mathrm{o}}}=\frac{\pi^{2}}{8} \frac{I_{\mathrm{o}}}{V_{\mathrm{o}}} \frac{1}{n^{2}} Z_{\mathrm{o}}=\frac{\pi^{2}}{8} \frac{P_{\mathrm{o}}}{\left(n V_{\mathrm{o}}\right)^{2}} Z_{\mathrm{o}}
$$

the time domain steady-state model of the converter with the proposed two parameter modulation strategy can be derived as

$$
\begin{gathered}
i_{\mathrm{Lr}}(0)+i_{\mathrm{Lr}}(0) \cos \gamma+\left[1-M-v_{\mathrm{Cr}}(0)\right] \sin \gamma \\
-0.5 \sin \left(\gamma-\theta_{D}\right)=0(7 \mathrm{a}) \\
0.5+v_{\mathrm{Cr}}(0)-\left[M-0.5 \cos \left(\gamma-\theta_{D}\right)\right. \\
\left.+\left[1-M-v_{\mathrm{Cr}}(0)\right] \cos \gamma-i_{\mathrm{Lr}}(0) \cos \gamma\right]=0(7 \mathrm{~b}) \\
i_{\mathrm{Lr}}(0)(\cos \gamma-1)+\left[1-M-v_{\mathrm{Cr}}(0)\right] \sin \gamma \\
-0.5 \sin \left(\gamma-\theta_{D}\right)-M \gamma / k=0(7 \mathrm{c}) \\
{\left[1-M-v_{\mathrm{Cr}}(0)\right](1-\cos \gamma)+0.5\left[\cos \left(\gamma-\theta_{D}\right)-1\right]} \\
+i_{\mathrm{Lr}}(0)[\sin \gamma-\gamma]-M \gamma^{2} / 2 k-8 M Q \gamma / \pi^{2}=0(7 \mathrm{~d})
\end{gathered}
$$

The model - a non-linear system of equations - is solvable with numerical solver packages for e.g. MATLAB with its function $f$ solve, for $\theta_{\mathrm{D}}$ and $\gamma$ that correspond to the duty ratio and normalized frequency to be applied for a desired $M$ at designed values of $k$ and $Q$. Fig. 6 shows the duty ratio and normalized frequency variations over $M \in\left[\begin{array}{ll}0.5 & 1\end{array}\right]$ for $k=8$ and $Z_{\mathrm{o}}=20 \Omega$, for different load conditions. While the duty ratio is monotonically increasing, the normalized frequency characteristic curves have parabolic natures, that in an actual implementation would require a non-linear controller. It can also be observed that the frequency compensation required to maintain the converter in zero circulating current mode, has a rapidly peaking behaviour at light loads. A maximum frequency limit can be set above which the converter is freezed and operated with duty ratio only as in [7], based on an optimum between switching and conduction losses in the converter.

\section{CONVERTER PERformance EVAluation AND BENCHMARKING}

The performance of the proposed converter is evaluated against a conventional wide range LLC converter as well as against the converter in [7] for the $400 \mathrm{~V} / 18-36 \mathrm{~V}$ dc-dc stage of a $24 \mathrm{~V} / 3 \mathrm{~kW}$ battery charger. For the comparison to 


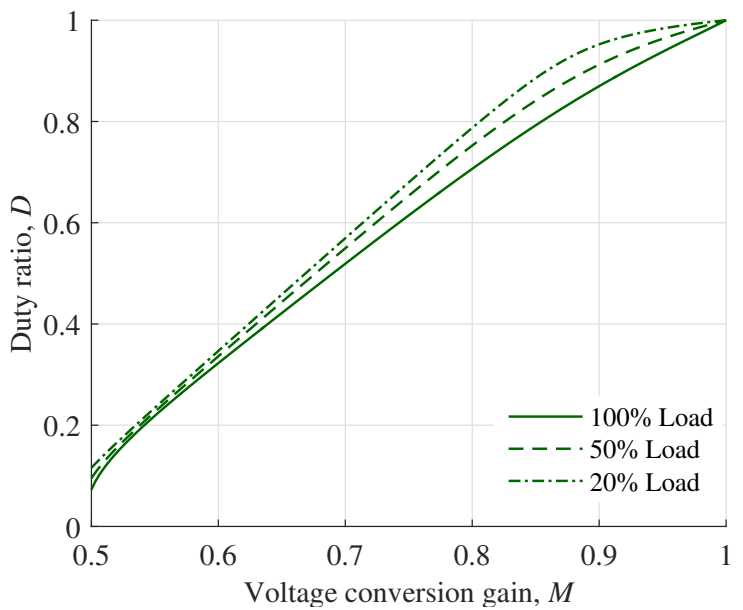

(a)

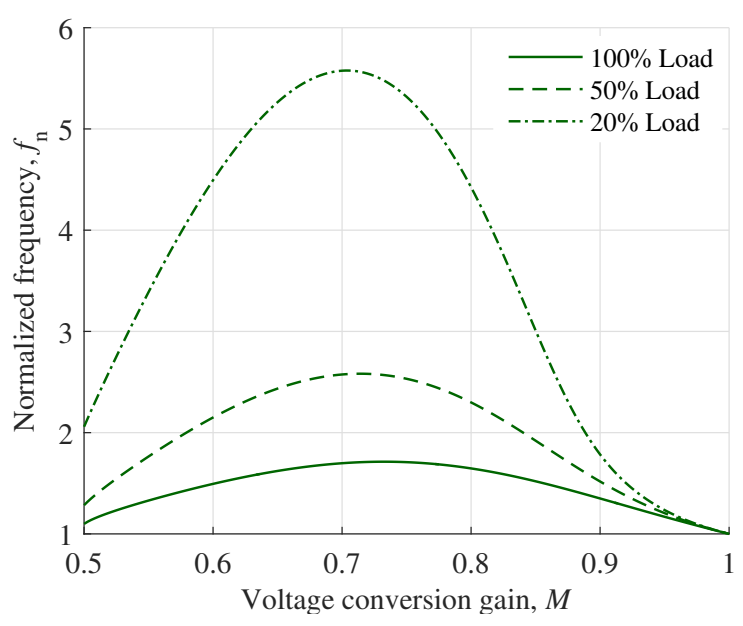

(b)

Fig. 6. Control to output characteristics of converter

be fair, the benchmark LLC converter is designed according to the methodology proposed in [11] to 1) maximize its tank characteristic impedance while keeping the converter in the DCMB2/PO mode throughout $M \in\left[\begin{array}{ll}1 & 2\end{array}\right]$ and 2) ensure ZVS at zero-load operation at minimum conversion gain with a maximum dc input voltage of $420 \mathrm{~V}$ and a maximum switching frequency of $1.35 f_{\mathrm{n}}$, specified. The proposed converter is designed based on 1) the minimum value of tank characteristic impedance above which the resonant tank currents cannot be sensibly reduced and 2) the maximum $k$ to ensure ZVS throughout the entire voltage and load range. The converter in [7] is designed in a similar way and results in the same parameters as listed in Table I. All converters full load switching frequencies fall within $100 \mathrm{kHz}-200 \mathrm{kHz}$.

In contrast to the conventional LLC converter, the proposed converter's normalized frequency $f_{\mathrm{n}}>1$ for boosting action (Fig. 6(b)), keeping the magnetics volume low while the step down characteristic of the converter halves the required transformer turns ratio. The gain for $M \in\left[\begin{array}{ll}0.5 & 1\end{array}\right]$ is not constrained by the quality factor and inductance ratio as in the case of the LLC converter, which simplifies the optimal

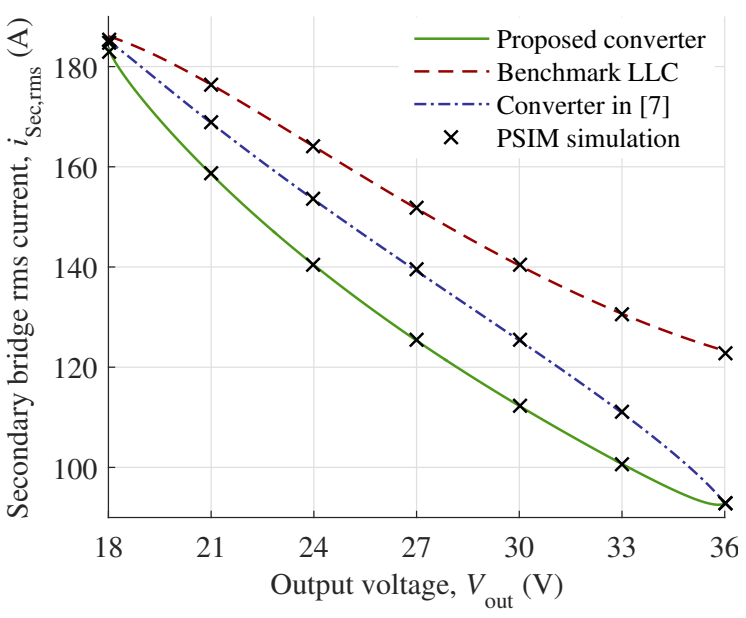

(a)

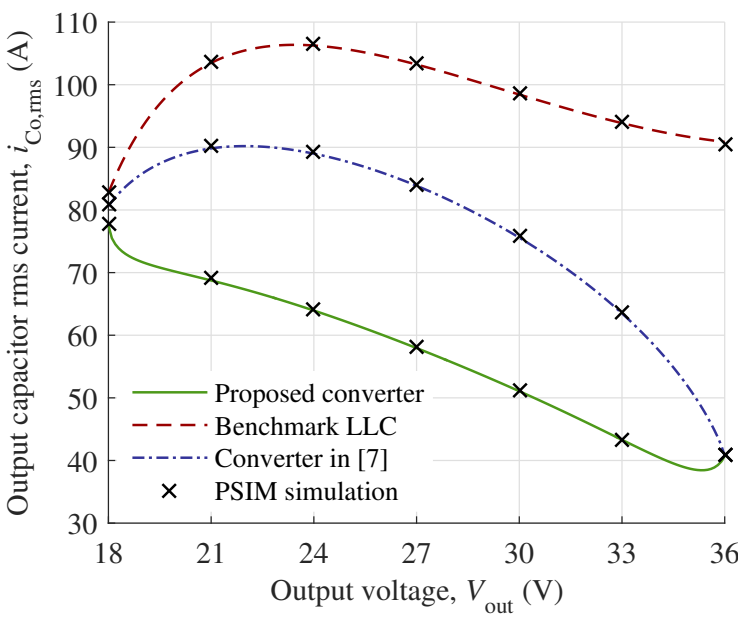

(b)

Fig. 7. Analytical comparison of the proposed converter's currents against two other converters for $400 \mathrm{~V} / 18-36 \mathrm{~V}, 3 \mathrm{~kW}$ constant power (a) secondary bridge rms currents and (b) output capacitor rms currents

design of the resonant tank.

Converter rms currents are analytically determined for $V_{\mathrm{o}} \in$ [18V 36V], based on (3), (4) and (7). Corresponding timedomain models of the LLC converter operating in DCMB2/PO mode [3] as well as that of [7] are also solved for their respective rms currents. The accuracy of the calculated currents for

TABLE I

DESIGNED PARAMETERS FOR ANALYTICAL COMPARISONS

\begin{tabular}{r||l|l|l}
\hline Parameters & $\begin{array}{l}\text { Proposed } \\
\text { converter }\end{array}$ & $\begin{array}{l}\text { Benchmark } \\
\text { LLC }\end{array}$ & $\begin{array}{l}\text { Converter in } \\
{[7]}\end{array}$ \\
\hline$n$ & 11 & 22 & 11 \\
$L_{\mathrm{r}}(\mu \mathrm{H})$ & 23.9 & 22.3 & 23.9 \\
$L_{\mathrm{m}}(\mu \mathrm{H})$ & 287 & 89.1 & 287 \\
$C_{\mathrm{r}}(\mathrm{nF})$ & 106 & 28.4 & 106 \\
$k$ & 12 & 4 & 12 \\
$Z_{\mathrm{o}}$ & 15 & 28 & 15 \\
$f_{\mathrm{r} 1(\mathrm{kHz})}$ & 100 & 200 & 100 \\
$C_{\mathrm{oss}}(\mathrm{pF})$ & 200 & 200 & 200 \\
Deadtime $(\mathrm{ns})$ & 100 & 100 & 100
\end{tabular}




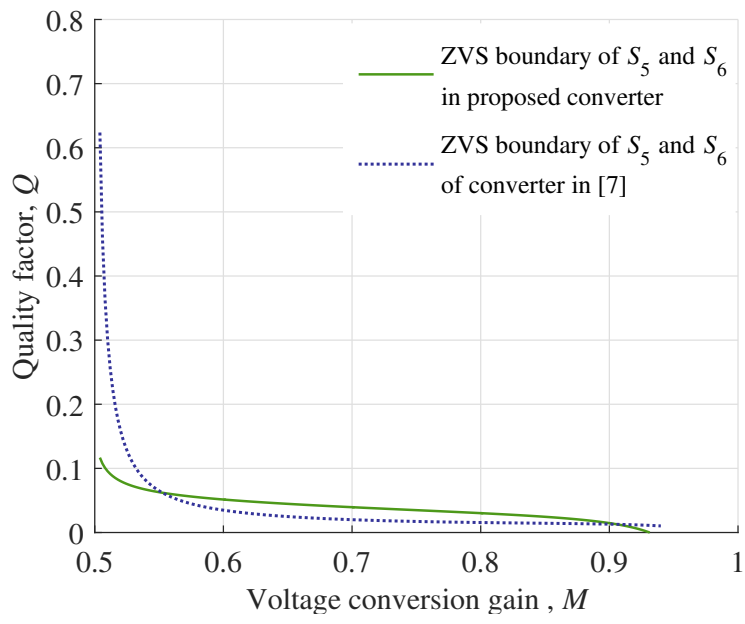

Fig. 8. ZVS boundaries of auxiliary switches $S_{5}$ and $S_{6}$ of proposed converter and the converter in [7]

all three converters are validated by PSIM circuit simulation. For this high step-down battery charger application, secondary side currents are particularly important to keep in check for conduction losses, cooling and filtering requirements to be minimized. Fig. 7 shows the full load secondary bridge rms current, $i_{\mathrm{Sec}, \mathrm{rms}}$ and the output capacitor rms currents, $i_{\mathrm{Co}, \mathrm{rms}}$ for the three designs. The proposed converter allows a solid reduction of current stresses in the secondary bridge and a significant reduction in output capacitor rms currents.

The proposed converter's main switches $S_{1}-S_{4}$ achieve ZVS down to zero load and auxiliary switches $S_{5}$ and $S_{6}$ lose ZVS only at extremely light loads. Their ZVS range is derived based on the parameters in Table I and shown in Fig. 8 . The ZVS boundary when the converter is controlled at fixed frequency as in [7], [8] is also plotted on the same diagram. Regions under each curve are their respective non-ZVS range. It can be observed that the proposed converter although having slightly lower ZVS range because of lower resonant current across the gain range, has an improved ZVS characteristic at very low $M$, where in comparison [7] loses ZVS of $S_{5}$ and $S_{6}$ for fairly high power levels.

TABLE II

DESIGNED PARAMETERS FOR EXPERIMENTAL COMPARISONS

\begin{tabular}{r||l|l|l}
\hline Parameters & $\begin{array}{l}\text { Proposed } \\
\text { converter }\end{array}$ & $\begin{array}{l}\text { Benchmark } \\
\text { LLC (Half- } \\
\text { bridge) }\end{array}$ & $\begin{array}{l}\text { Converter in } \\
{[7]}\end{array}$ \\
\hline$n$ & 11 & 11 & 11 \\
$L_{\mathrm{r}}(\mu \mathrm{H})$ & 36.2 & 19.2 & 36.2 \\
$L_{\mathrm{m}}(\mu \mathrm{H})$ & 286 & 76.7 & 286 \\
$C_{\mathrm{r}}(\mathrm{nF})$ & 68 & 33 & 68 \\
$k$ & 7.9 & 4 & 7.9 \\
$Z_{\mathrm{o}}(\Omega)$ & 23 & 24 & 23 \\
$f_{\mathrm{r} 1(\mathrm{kHz})}$ & 100 & 200 & 100 \\
$C_{\mathrm{oss}}(\mathrm{pF})$ & 100 & 100 & 100 \\
Deadtime $(\mathrm{ns})$ & 100 & 70 & 100 \\
$f_{\mathrm{s}}$ range $(\mathrm{kHz})$ & $100-180$ & $140-200$ & 100
\end{tabular}

\section{EXPERIMENTAL VALIDATION}

A $500 \mathrm{~W}, 400 \mathrm{~V} / 18-36 \mathrm{~V} \mathrm{GaN}$ prototype is built to validate the operating principles of the converter. The primary bridge is made of GS66506T GaN HEMTs, ADuM4121-1 gate drivers and NKE0509DC isolated power supplies. The secondary bridge consists of STPS61H100C schottky rectifiers. The bridges are built on two different PCBs, to facilitate their reconfiguration into similar converter topologies with adjustment of the liaising resonant tank and transformer, for

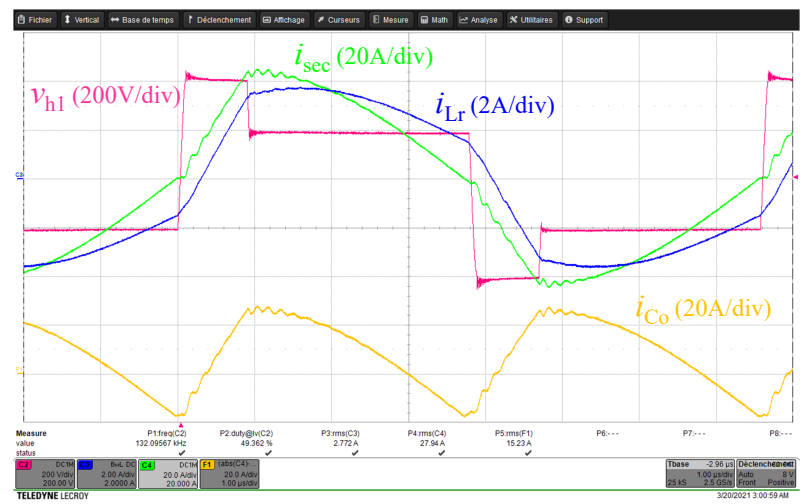

(a)

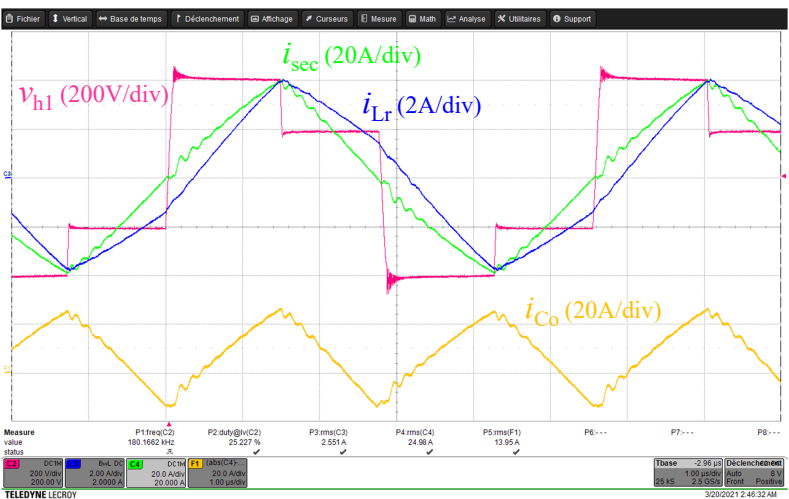

(b)

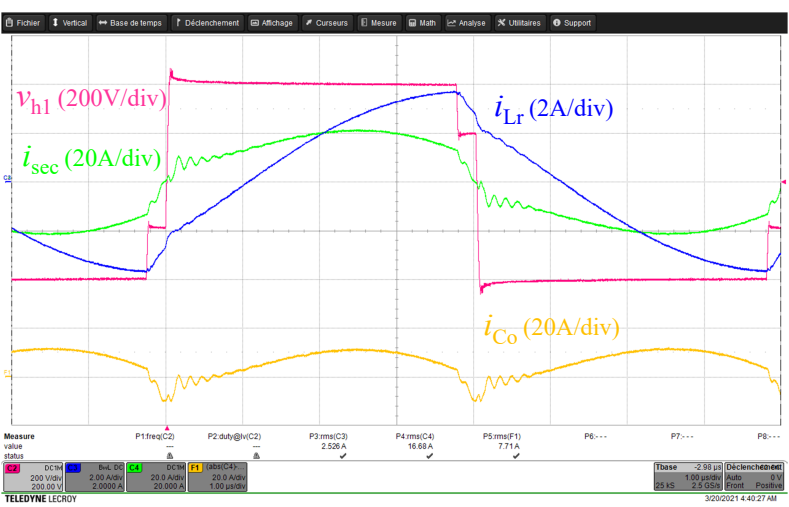

(c)

Fig. 9. Experimental waveforms of proposed converter at $V_{\text {in }}=400 \mathrm{~V}$ and $P_{\mathrm{O}}=500 \mathrm{~W}$ across the output voltage range - (a) $V_{\mathrm{O}}=21 \mathrm{~V}: D=0.340$, $f_{\mathrm{s}}=158 \mathrm{kHz}(\mathrm{b}) V_{\mathrm{o}}=27 \mathrm{~V}: D=0.652, f_{\mathrm{s}}=180 \mathrm{kHz}$ and (c) $V_{\mathrm{o}}=33 \mathrm{~V}:$ $D=0.920, f_{\mathrm{s}}=124 \mathrm{kHz}$ 


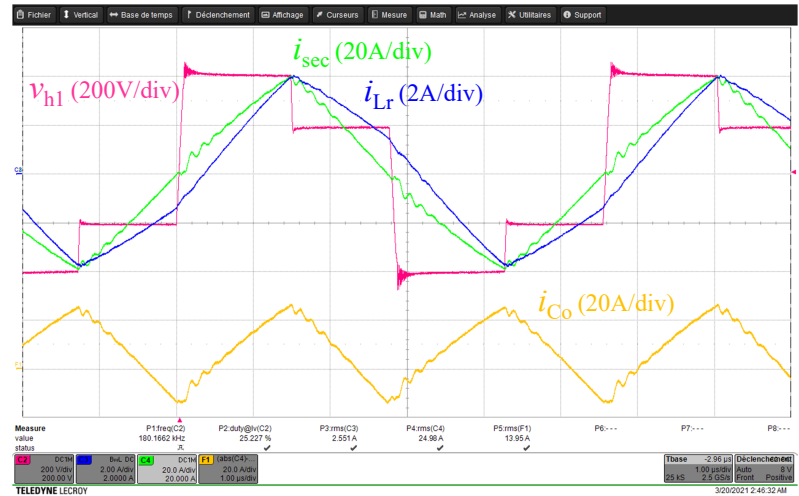

(a)

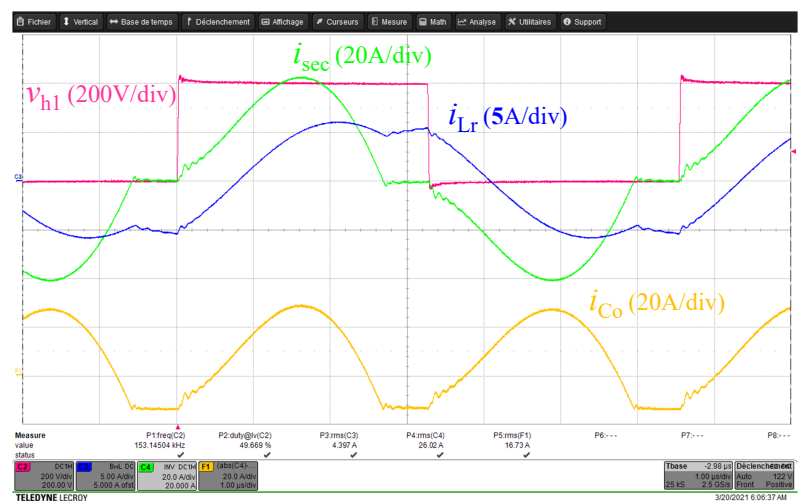

(b)

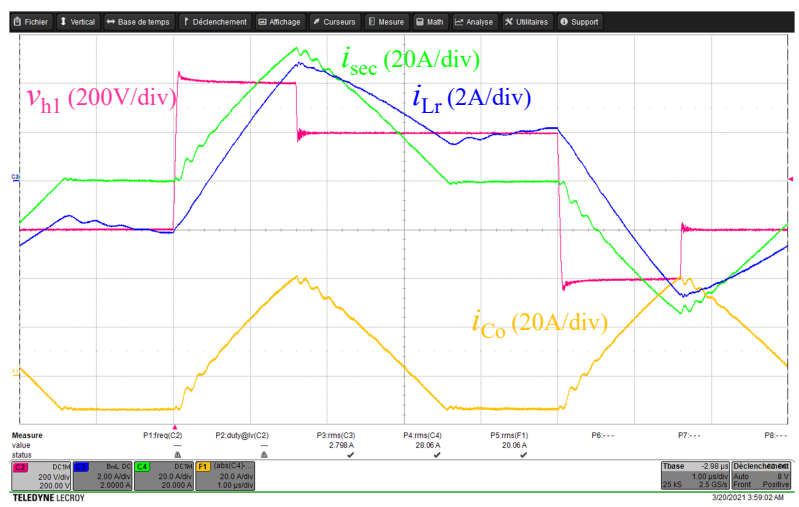

(c)

Fig. 10. Experimental comparison of proposed converter waveforms against two other converters at $V_{\text {in }}=400 \mathrm{~V}, P_{\mathrm{O}}=500 \mathrm{~W}$ and $V_{\mathrm{O}}=24 \mathrm{~V}-$ (a) proposed converter: $D=0.524, f_{\mathrm{s}}=180 \mathrm{kHz}$ (b) benchmark LLC converter: $D=1$, $f_{\mathrm{s}}=153 \mathrm{kHz}$ and (c) converter in [7]: $D=0.320, f_{\mathrm{s}}=100 \mathrm{kHz}$

platform-alike performance comparisons and benchmarking.

The proposed converter's waveforms: primary bridge voltage $v_{\mathrm{h} 1}$, resonant current $i_{\mathrm{Lr}}$, secondary bridge current, $i_{\mathrm{Sec}}$ and output capacitor current, $i_{\mathrm{Co}}$ for three operating points across the output voltage range are shown in Fig. 9. Design parameters are listed in Table II. The two level step voltage $v_{\mathrm{h} 1}$ applied to the resonant tank at a specified frequency and duty ratio is shown to effectively spread the secondary current over the switching period, thus eliminating the zero power exchange interval, as indicated by the zero crossing

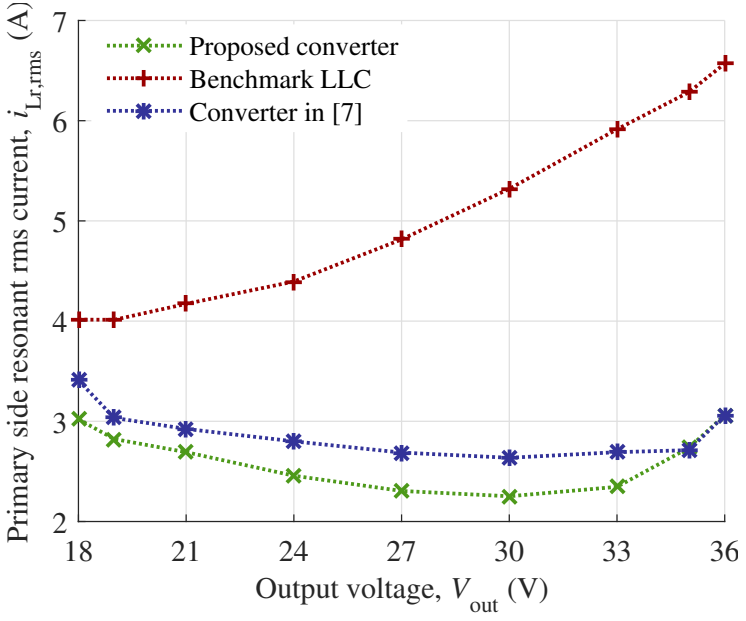

(a)

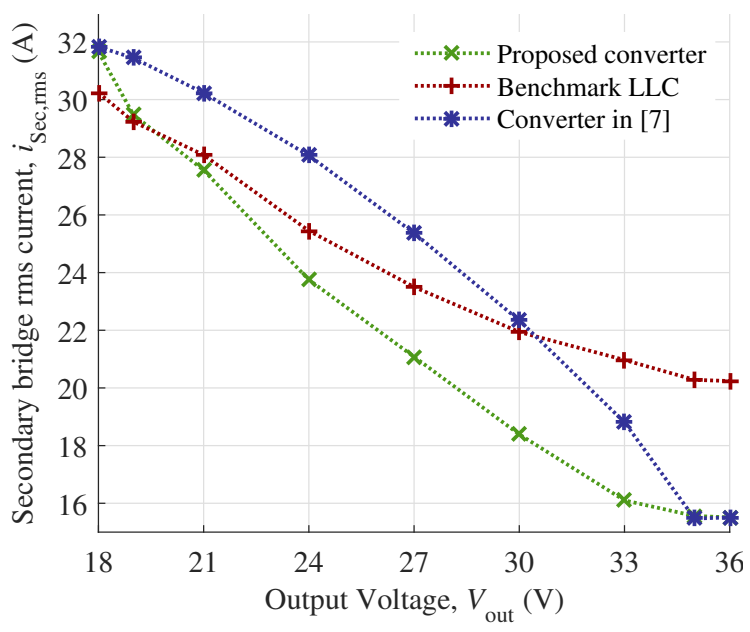

(b)

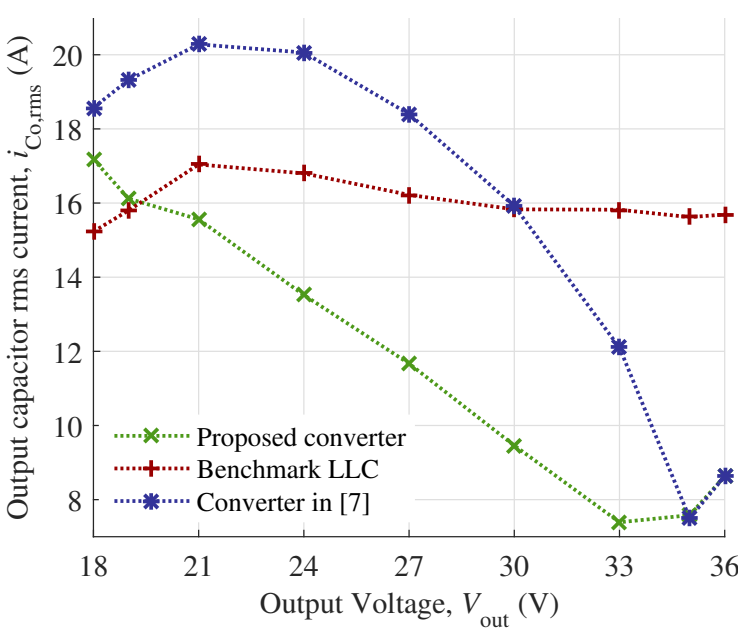

(c)

Fig. 11. Experimental comparison of proposed converter currents against two other converters at $V_{\text {in }}=400 \mathrm{~V}$ and $P_{\mathrm{o}}=500 \mathrm{~W}$ across the output voltage range - (a) primary side resonant currents (b) secondary bridge currents and (c) output capacitor currents

of $i_{\text {Sec }}$ just before the end of the half period. This translates 
into an efficiently utilized switching cycle by the secondary side current, of utmost importance in low output voltage/high current applications for conduction losses minimization.

The non-appearance of the zero power transfer interval, also signifies the suppression of parasitic ringing between the transformer secondary winding leakage inductance and diodes output capacitance frequently observed in LLC converters during the $L_{\mathrm{m}}-L_{\mathrm{r}}-C_{\mathrm{r}}$ resonance interval when the secondary is decoupled from the primary bridge. This may have a positive impact on the EMI performance of the proposed converter.

The analytical comparisons started in Section IV are pursued experimentally based on the same design methodologies to evaluate the performance of the converter. The benchmark LLC here is designed in its half bridge form rather than its full bridge configuration 1) as a more realistic design reference at this power level i.e. $<1 \mathrm{~kW}$ and 2) allowing the same transformer with identical turns ratio to be used for all three converters. Design parameters are given in Table II.

Waveforms for $v_{\mathrm{h} 1}, i_{\mathrm{Lr}}, i_{\mathrm{Sec}}$ and $i_{\mathrm{Co}}$ at nominal battery voltage $V_{\mathrm{o}}=24 \mathrm{~V}$, are shown in Fig. 10. At this operating point, the $L_{\mathrm{m}}-L_{\mathrm{r}}-C_{\mathrm{r}}$ resonance interval starts appearing for the LLC converter, Fig. 10(b), and the secondary bridge discontinuous conduction mode only worsens for higher voltages. For the converter in [7], Fig. 10(c), the operating point $V_{\mathrm{o}}=24 \mathrm{~V}$, falls within its worse case $i_{\mathrm{Sec}}$ discontinuous conduction mode region, but improves for higher operating voltages when approaching the second pure resonance point at $V_{\mathrm{o}}=36 \mathrm{~V}$. Fig. 11 illustrates the variation of the rms values of primary side resonant current, secondary bridge and output capacitor currents recorded on the three prototypes for $V_{\mathrm{o}} \in[18 \mathrm{~V} 36 \mathrm{~V}]$ at $500 \mathrm{~W}$ constant power. Except at very low output voltage $V_{\mathrm{o}}<20 \mathrm{~V}$ where it is slightly outperformed by the LLC converter - operating in the vicinity of its most efficient series resonance point - the superiority of the proposed converter is overt.

\section{CONCLUSION}

A two-degrees-of-freedom modulation technique, based on minimal structural change to the input bridge, is proposed to address the highly discontinuous mode of power transfer in wide range LLC converters. A precise time-domain model of the converter is developed and used for designing, validating and evaluating its performance against state-of-the-art converters. Analytical, simulation and experiments run on a
$500 \mathrm{~W}, 400 \mathrm{~V} / 18-36 \mathrm{~V}$ GaN prototype confirm the effectiveness of the proposed method in driving the system into boundary conduction mode at all operating points, thereby eliminating primary side circulating currents, lowering secondary side peak and rms currents, and significantly reducing output filter capacitor currents, for attaining higher power efficiency and density targets.

\section{ACKNOWLEDGMENT}

Authors would like to thank François Beaucamp and Damien Brelivet, from Enersys S.A.R.L, for their support during the hardware testing phase.

\section{REFERENCES}

[1] B. Yang, F. C. Lee, A. Zhang, and G. Huang, "Llc resonant converter for front end dc/dc conversion," in APEC. Seventeenth Annual IEEE Applied Power Electronics Conference and Exposition (Cat. No. 02CH37335), vol. 2, pp. 1108-1112. IEEE, 2002.

[2] J. F. Lazar and R. Martinelli, "Steady-state analysis of the llc series resonant converter," in APEC 2001. Sixteenth Annual IEEE Applied Power Electronics Conference and Exposition (Cat. No. 01CH37181), vol. 2, pp. 728-735. IEEE, 2001.

[3] X. Fang, H. Hu, Z. J. Shen, and I. Batarseh, "Operation mode analysis and peak gain approximation of the llc resonant converter," IEEE transactions on power electronics, vol. 27, no. 4, pp. 1985-1995, 2011.

[4] W. Chen, P. Rong, and Z. Lu, "Snubberless bidirectional dc-dc converter with new cllc resonant tank featuring minimized switching loss," IEEE Transactions on industrial electronics, vol. 57, no. 9, pp. 3075-3086, 2009.

[5] W. Song and B. Lehman, "Dual-bridge dc-dc converter: A new topology characterized with no deadtime operation," IEEE Transactions on Power Electronics, vol. 19, no. 1, pp. 94-103, 2004.

[6] P. A. Bezerra, F. Krismer, R. M. Burkart, and J. W. Kolar, "Bidirectional isolated non-resonant dab dc-dc converter for ultra-wide input voltage range applications," in 2014 International Power Electronics and Application Conference and Exposition, pp. 1038-1044. IEEE, 2014.

[7] X. Sun, X. Li, Y. Shen, B. Wang, and X. Guo, "Dual-bridge llc resonant converter with fixed-frequency pwm control for wide input applications," IEEE Transactions on Power Electronics, vol. 32, no. 1, pp. 69-80, 2016.

[8] Y. Shen, H. Wang, A. Al-Durra, Z. Qin, and F. Blaabjerg, "A structurereconfigurable series resonant dc-dc converter with wide-input and configurable-output voltages," IEEE Transactions on Industry Applications, vol. 55, no. 2, pp. 1752-1764, 2018.

[9] Y. Wei, Q. Luo, and H. E. C. A. Mantooth, "Hybrid control strategy for llc converter with reduced switching frequency range and circulating current for hold-up time operation," IEEE Transactions on Power Electronics, 2021.

[10] H.-P. Park and J.-H. Jung, "Pwm and pfm hybrid control method for llc resonant converters in high switching frequency operation," IEEE Transactions on Industrial Electronics, vol. 64, no. 1, pp. 253-263, 2016.

[11] J. Deng, S. Li, S. Hu, C. C. Mi, and R. Ma, "Design methodology of llc resonant converters for electric vehicle battery chargers," IEEE Transactions on Vehicular Technology, vol. 63, no. 4, pp. 1581-1592, 2013. 